\title{
Urban Planning and Cyber-Citizenry in China
}

How the 2.0 opposition organises itself

\section{Nicolas Douay}

Translator. Jonathan Hall

\section{(2) OpenEdition}

\section{Journals}

\section{Electronic version}

URL: http://journals.openedition.org/chinaperspectives/5472

DOI: 10.4000/chinaperspectives.5472

ISSN: 1996-4617

\section{Publisher}

Centre d'étude français sur la Chine contemporaine

\section{Printed version}

Date of publication: 1 January 2011

Number of pages: $77-79$

ISSN: 2070-3449

\section{Electronic reference}

Nicolas Douay, «Urban Planning and Cyber-Citizenry in China », China Perspectives [Online], 2011/1

2011, Online since 30 March 2014, connection on 15 September 2020. URL : http://

journals.openedition.org/chinaperspectives/5472 


\title{
Urban Planning
}

\section{and Cyber-Citizenry in China}

\author{
How the 2.0 opposition organises itself
}

\author{
NICOLAS DOUAY*
}

l: November 2010, the number of Chinese using the internet reached 450 million, representing a 20 percent increase in one year. Access to the various international networks such as YouTube, Twitter, Flicker, and Facebook is forbidden, but they have Chinese equivalents. The government makes use of this fact to maintain control over the web by preventing the development of dissident movements. Accordingly, the Chinese web has been cleared of politically sensitive websites. Nonetheless, Chinese surfers play at cat-and-mouse with the censors, sometimes by recourse to innuendo, and large numbers of them have invaded the blogosphere and other social networking sites on the new 2.0 web, (1) which have become uncensored forums for public expression and opposition. (2) Consequently, it quite often happens that various issues create a stir and force the authorities to react. In this way, problems linked to the rapid urbanisation of China have given rise to the social mobilisation of internet users. ${ }^{(3)}$

The French political scientist Michel Offerlé (4) makes a distinction between the three major resources that can be mobilised by social movements. The first of these is their number, which enables the mobilisation of considerable manpower. The second is the level of their expertise, which depends on the competence of the members of the group and/or their ability to involve people whose acknowledged competence brings with it the power to persuade others. The third is their reliance on controversy to denounce a particular situation and arouse public awareness. The participatory aspect of the 2.0 web affords easy access to these three resources.

Web users' organisation into networks enables large scale collection and diffusion of information, plus the capacity to present a well-informed alternative viewpoint capable of shaping public opinion and, quite often, forcing the official media to take up the issues raised by protests. For its part, the government has also grasped that there are advantages in drawing on the same information to shape its own reaction, sometimes by offering its own justifications to avoid rumours being spread, or even, on some occasions, by introducing alterations to its urban policies. In effect, official policies are put under surveillance by these cyber-citizens, who are able to challenge their legitimacy. In light of these developing forms of mobilisation in cyber-space, we can raise questions about the contribution made by these new tools by enquiring into the forms, objectives, and effectiveness of these urban social movements, especially in view of their collaborative aspect.

At the end of 2010, two experiences led to the establishment of participatory sites that asked internet users to provide information in order to denounce current urban policies. By acting as an intermediary for a large number of contributors, their maps, which are compiled collectively, draw primarily on the controversial nature of a particular situation, but they are also aimed at developing a more broadly informed alternative outlook to oppose that of the authorities. In mainland China (see the "bloody map" insert), this mobilisation is brought to bear on violations related to property development, whereas in Hong Kong it focuses on environmental issues (see the "citizen map" insert).

\section{The real estate blood map}

At first cyber-citizens chose to provoke controversy by relying on the shock value of a situation. For example, in the spring of 2007, the Chongqing "nail house" - the only one to escape a housing development project - gained international renown thanks to the "Zuo.la" (or Zola) blogger. ${ }^{(5)}$ This led to the owner being offered improved compensation. The story also put a spotlight, both in China and far beyond its borders, on the wider issue of the forcible eviction of residents of modest means in order to clear space for new apartment blocks, often for the purpose of real estate speculation.

In 2010, an anonymous internet contributor using the pseudonym Xuefangditu, or "real estate blood map," compiled a list of violent evictions linked to property development projects in China. This blogger's motive was to denounce the rapid pace of urbanisation that is destroying the lives of many citizens, and to create a movement to boycott those new developments where there had been bloodshed.

Nicolas Douay is Associate Professor of urban planning at Paris-Diderot University (Paris 7) and a researcher in the Geographie - Cités laboratory (CRIA team). He holds a PhD jointly supervised by the University of Montreal and Paul Cézanne University (Aix-Marseille 3). He did a postdoctoral internship at the French Centre for Research on Contemporary China (CEFC - Hong Kong). His research compares urban planning approaches between Asia (China \& Hong Kong), Europe (France) and North America (Canada) and focuses on the process of metropolisation particularly with regard to urban policies and territorial planning processes.

1. A concept put forward by Tim O'Reilly in 2005 , which emphasises the move towards a participatory use of the web. This means that the internet becomes a channel for collective intelligence in which each user forms part of a social network. To put it clearly, the 2.0 web actively includes the user of the web by enabling him to interact with others and become part of a community.

2. Pierre Haski, Internet et la Chine, Paris, Seuil, 2008; Guobin Yang, The Power of the Internet in China: Citizen Activism Online, NYC, Columbia University Press, 2009; Zixue Tai, The Internet in China: Cyberspace and Civil Society, NYC, Routledge, 2006; Hermès, no. 55, "Société civile et internet en Chine et Asie Orientale," 2010; Séverine Arsène, "Online Discussions in China: The Collaborative Development of Specific Norms for Individual Expression," China Perspectives no. 2, 2008, pp. 83-93.

3. Network users who mobilise in support of the movement to democratise the regime are also to be found on the internet, but they participate in far riskier forms of mobilisation, as can be seen from the fate of the imprisoned dissident $\mathrm{Hu}$ Jia and, more recently, Liu Xiaobo, who also used the internet to publicise his Charter '08.

4. Michel Offerlé, Sociologie et groupes d'intérêt, Paris, Monchrestien, 1996.

5. http://zuo.la/. 


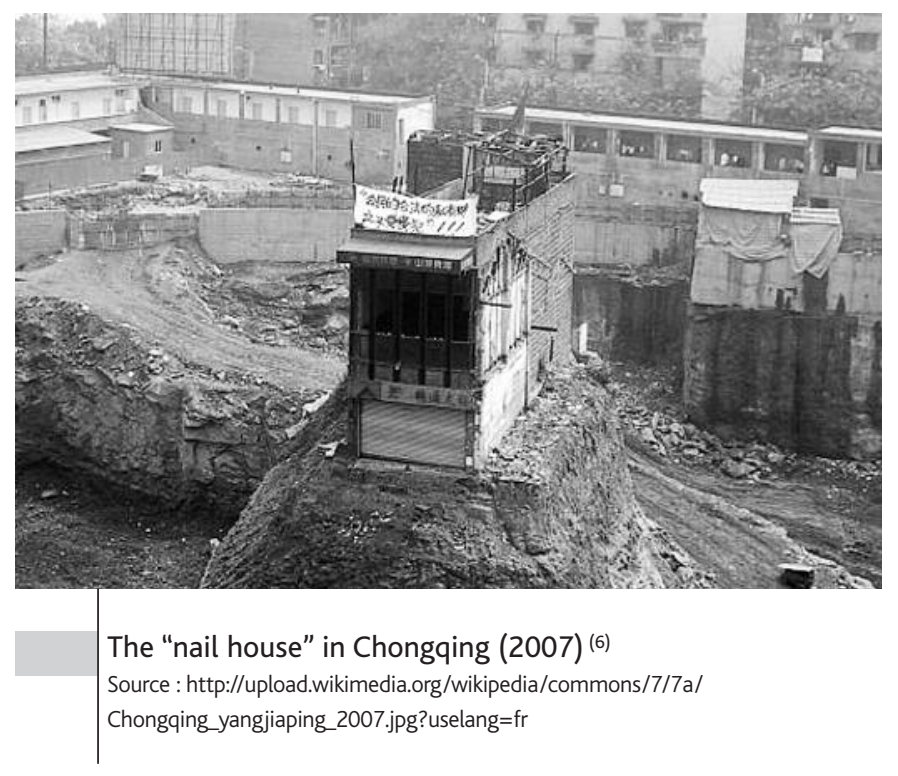

The map was published on 8 October 2010, and on 20 October the Xinhua News Agency published an article about it, leading to ten other Chinese publications taking up the story a month later. By late December 2010, a Google search for the phrase "bloody map" produced more than $1,640,000$ hits. According to the figures released by Baidu, China's version of Google, Chinese people showed more interest in this map than in $\mathrm{Li}$ Yuchun, the celebrity winner of a reality TV show.

This blog makes use of Google Maps and, following the pattern set by Wikipedia, it calls for the participation of other web users to collect, organise, verify, and discuss the information. The user can zoom in on the map and find the exact location of an incident whose nature is represented by a small icon: a hospital bed symbolises a fatality, a flame indicates a selfimmolation, and a volcano a major demonstration. A question mark indicates when information has not yet been verified.

Various events are narrated, like the self-immolation of Tang Fuzhen in November 2010. After a long period of resisting the demolition of her house on the outskirts of Chengdu, this 47-year old woman doused herself in petrol on the roof of her house while the demolition team burst in and beat up her sister and husband. She died in hospital two weeks later after horrible suffering. A mobile phone video of her immolation was broadcast widely on the web and even made it into a CCTV report. This event deeply affected public opinion and increased awareness of the side-effects of the forced evictions linked to the country's galloping urbanisation.

In addition to registering the controversial aspects of incidents as the blogs do, this collaborative map-making records the number of such incidents and acquires lasting value by allowing the accumulation of such information. This mapping could well become a useful tool for following and evaluating the urban policies of the government, as well as providing guidance for making ethical choices in local rehousing policies.

\section{The Hong Kong Citizen Map}

The Hong Kong Special Administrative Region presents a strikingly dual aspect. Only 30 percent of the territory consists of densely occupied urban spaces crammed with high rise buildings, while the remaining 70 percent is green space, and 40 percent even enjoys governmental protection. However, in view of the large expanses of land subject to official inspection, the

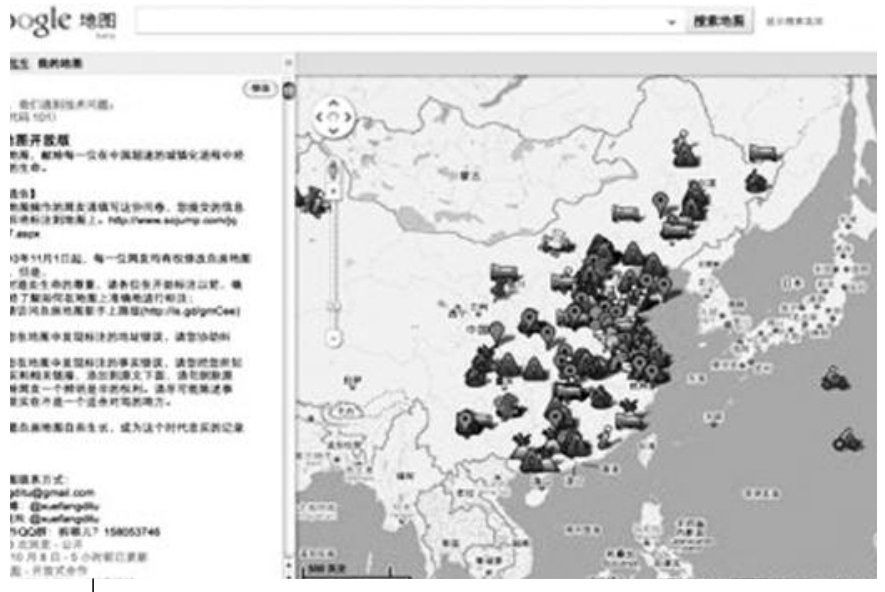

The "Bloody Map" screen (recorded on December 1st 2010) (7)

authorities' resources appear rather limited and poorly co-ordinated, with only a few hundred officials distributed thinly across three different organisations. In addition, the rather unsubstantial fines and penalties imposed for contravention have bred a certain sense of impunity within the construction industry, which enjoys a great deal of support in the Legislative Council. That is why 93 percent of the 20,485 complaints filed between 2005 and 2009 about illegal building in green space areas were made by members of the public.

In view of this situation, the leading English language newspaper in Hong Kong, the South China Morning Post, launched an initiative that makes use of the Ushaihidi technology developed in Kenya. (9) Using an interactive website, the newspaper sets out to expose attacks on the environment reported by members of the public. This project relies on environmentally aware citizens and their love of nature as well as their sense of responsibility. This approach is summed up in the website's logo: "For Hong Kong by Hong Kong."

The need for this tool arose out of an awareness of a major increase in environmental depredation, ranging from illegal dumping to building on protected land, which was causing the destruction of green areas. In 2010, the main controversy focused on the ruin of an area of the Tai Long Sai Wan nature reserve in Sai Kung. That is where a businessman, Simon Lo Lin-Shing, wanted to build an impressive villa with a swimming pool, tennis courts, botanical gardens, and artificial pools. Then the press announced that his project was located on an archaeological site, and ecologists revealed that site preparation work and lorry traffic had already seriously damaged the environment in protected areas. The government reacted by imposing a three-year moratorium.

6. Source: http://fr.wikipedia.org/wiki/Fichier:Chongqing_yangjiaping_2007.jpg

7. Source: http://maps.google.com/maps/ms?brcurrent=3,0x35cab73c2e5c4465:0x946f70601c3d 2630,0, 0x34354978b41cab51:0xf168d14d8f0a2226percent3B5,0,0\&ie=UTF8\&hl=zh-CN\&msa= $0 \& m s i d=111560301092049321699.0004921 f 02 f 43 f 6 c 4 f 07 e \& l l=35.532226,100.283203 \& s p n=$ $55.026174,79.013672 \& z=4$.

8. Source: http://www.chinadaily.com.cn/china/2010-02/26/content_9506126_2.htm

9. The Ushaihidi technology is a composite application using Google Maps that allowed Kenyans to report and trace acts of violence in the days following the 2008 elections by accessing the social media sites through their mobile phones. This technology is developing and serving a variety of purposes in other countries. 


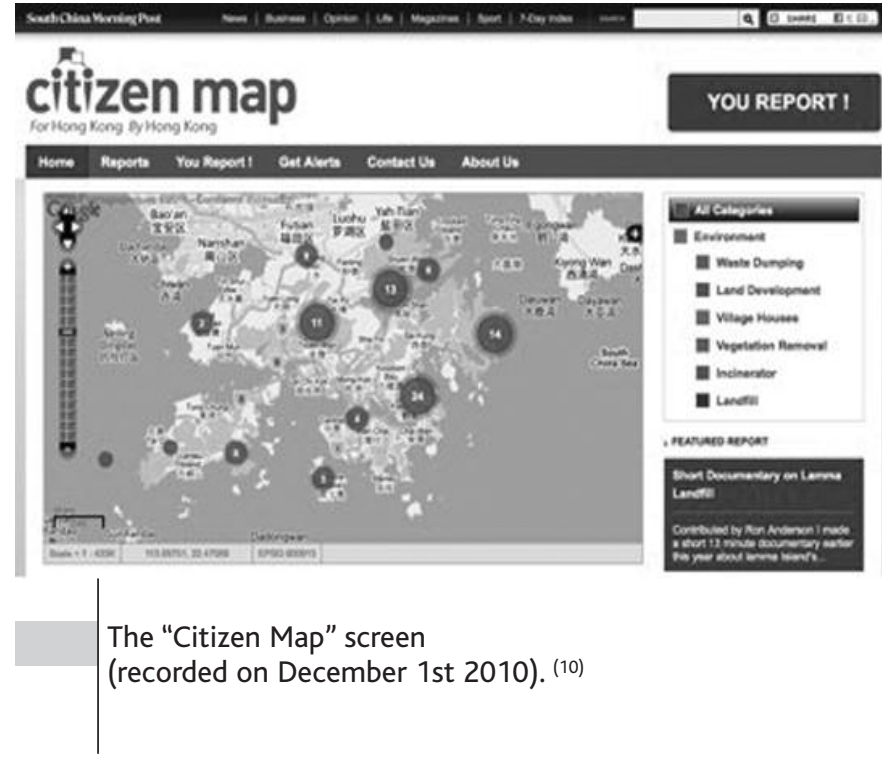

In light of these developments, the Citizen Map was devised to gather, verify, and publicise information, and thereby to exercise some influence on government policy. A week after its inception, 20 violations were reported, and that number had risen to nearly 120 by early January 2011 . The Citizen Map is currently still limited to environmental issues, but its official statement of aims says that it might be broadened to cover other matters in future.

This Citizen Map gives the inhabitants of Hong Kong the chance to become active supporters of a stronger civil society, enabling them to function as watch dogs over natural resources and keep a wary eye on the government and the rather too friendly relations it might build up with the most economically privileged circles.

\section{From the 2.0 urban struggles towards a collaborative urban planning?}

Compared with urban struggles that occurred in the 1960s and 1970s in Western countries, the forms of engagement and militancy are changing with the use of new digital tools. At a time when the internet seems more easily accessible to various urban social movements, new social networks are being transformed into forums for public debate provided with their own virtual space.

Firstly, these virtual platforms allow a partial by-passing of the police controls encountered in the physical public space (in mainland China but not in Hong Kong). Secondly, the internet sets up links between citizens while also allowing information to be gathered and slogans and demands to be passed on. Unlike older forms of urban struggle, the 2.0 opposition is able to bring together a large number of citizens in a short time, to highlight controversial situations, and to summon previously unexpected abilities thanks to the participatory processes themselves. The internet therefore makes it possible for less hierarchically organised urban social movements to emerge by providing a space for more individual forms of engagement, the lateral interconnectivity of which opens up the prospect of developing new kinds of collective intelligence.

Nonetheless, the aims of social mobilisation have not really changed in nature. These Chinese activists of the digital age, like their Western predecessors of the 1960s and 1970s, are fighting against evictions and the demolition of historic city quarters while advocating rehousing for all and, more broadly, the development of a city culture that would not exclude the vulnerable. This means, in effect, that they are demanding a "right to the city," adopting the viewpoint formulated earlier in the works of Henri Lefebvre. (11) The Hong Kong activists have added a further dimension by diversifying their aims. The demands emerging from the dynamics of these "new social movements" (12) are no longer purely materialist, but are also becoming post-materialist, as can be seen in the Citizen Map's concern with preserving the environment.

Over and above the conflicts that motivate these cyber-citizens, their demands amount to a denunciation of the ways in which the urban environment is currently managed, and even of the urban processes of production. This raises the question of a possible turning point in the culture of the city. The internet and social networks now enable public opinion to be shaped, and the emergence of a civil society to be actively supported. But it remains to be seen whether these new urban social movements will allow alternative forms of leadership to emerge, and whether this will have any repercussions within the real physical space of the city, even to the extent of having an effective influence on urban policies. Only the future will show whether this 2.0 opposition heralds a new set of urban practices that will be more collaborative, more sustainable, and even more inclusive.

\section{Translated by Jonathan Hall}

10. Source: http://citizenmap.scmp.com.

11. Henri Lefebvre, Le droit à la ville, Paris, Anthropos, 1968.

12. Alain Touraine, La voix et le regard, Paris, Seuil, 1978. 